\title{
Redislocation Following Zigzag Osteotomy Combined with Fibular Allograt for Dislocation of the Hip in Children
}

\author{
Nguyen Ngoc Hung \\ National Hospital for Pediatrics, Ha Noi, Viet Nam \\ Email: ngocyenhung@gmail.com
}

Received 10 March 2016; accepted 17 April 2016; published 20 April 2016

Copyright (C 2016 by author and Scientific Research Publishing Inc.

This work is licensed under the Creative Commons Attribution Non Commercial International License (CC BY-NC).

http://creativecommons.org/licenses/by-nc/4.0/

(c) (1) (9) Open Access

\section{Abstract}

We have reviewed 17 patients (18 hips) who required repeated open reduction for recurrent or persistent dislocation after a previous attempt at zigzag osteotomy combined with fibular allowgraft for developmental dysplasia of the hip (DDH). The purposes of this study were to examine predictors of redislocation and to evaluate the long-term outcomes after revision surgery. The mean age at primary open reduction was 24 months (13 to 36$)$. The median time to the recognition of failure was 4.6 months. The second reduction was performed at a mean age of 26.3 months (17 to 42$)$ and the mean age at final follow-up was 79.7 months (58 to 105) and the mean time follow-up was 42.4 months ( 37 to 76 ). We treated the hips with a new open reduction through an anteromedial approach. A constricted anteromedial capsule was always found as the main factor; all had an intact anteromedial capsule, and there was an inverted transverse ligament in five cases and a very tight psoas tendon in another four cases, eversion of the limbus in six cases, densing anterior capsule in five cases. We perform with the condition that all hips were cleared of scar tissue; five hips had adductor tenotomy; four hips required release of the psoas tendon, five eversion of the limbus. Release of the transverse ligament was required in five cases each. All hips with Kirschner wire through the femoral head into the acetabulum. Three hips required femoral shortening (average of $1.5 \mathrm{~cm}$ ); a derotation varus osteotomy was performed in two hips from ten and twelve weeks after repeated open reduction. Postoperative results according to modified McKay criteria for clinical: excellent: 3 of 18 hips (16.7\%); good: 8 of 18 hips (44.4\%); fair: 6 of 18 hips (33.3\%); and poor: 1 of 18 hips (5.6\%). We suggest that technical failure is usually the cause for redislocation with all that has an intact anteromedial capsule. There was an inverted transverse ligament, tight psoas tendon, eversion of the limbus, and densing anterior capsule. We believe that abnormal femoral version and femoral head dysplasia are also important factors for redislocation too. 


\section{Keywords}

\section{DDH, Redislocation, Anteromedial Approach, Salter Innominate Osteotomy, Femoral Shortening}

\section{Introduction}

The goal of treatment in developmental dysplasia of the hip (DDH) is to obtain and maintain a stable concentric reduction as quickly and as easily as possible. It is generally accepted that an open reduction is indicated for a developmental dislocation of the hip when a congruous, concentric and stable reduction is not achieved by closed methods. Uncommonly, open reduction is not successful, and re-dislocation occurs.

The reported incidence of re-dislocation after open reduction varies. It would appear to depend upon the approach used, the age of the patient at the time of initial reduction and, perhaps, the expertise of the surgeon. It has been reported to occur in $0 \%-8 \%$ following open reduction via an anterolateral approach [1] [2], and when the medial approach is used, this figure rises to $5 \%-14 \%$ [2]-[4].

Most instances of failure after a primary open reduction were the consequences of errors in surgical technique. Most of these hips had not had an adequate release of the anteromedial capsule and of the inferior articular structures [5] [6].

Previous reports have highlighted the problems of management of this difficult problem [1] [5] [6]. We present our experience with 17 patients (18 hips) who had redislocation following zigzag osteotomy combined with fibular allowed graft for DDH, and analyze the possible causes of failure and examine the outcome on both clinical and radiological basis.

The purpose of this study was to rigorously examine the risk for redislocation after open treatment for DDH in a consecutive series of patients who had received their entire care at 1 institution. Our secondary purpose was to evaluate the long-term outcomes after revision surgery.

\section{Material and Methods}

After obtaining approval from our institutional review board, we queried the surgical database at our center to identify all patients who had undergone an open reduction for the treatment of DDH with zigzag osteotomy and combined fibular allograft [7]. Patients with teratologic dislocations, neuromuscular or connective tissue disorders, and those patients with a history of a previous open hip procedure at another institution were excluded from the study.

Informed consent was obtained from all participants. The study had the approval of the Ethical Review Committee of our Institute and was carried out in accordance with the tenets of the Declaration of Helsinki.

Between 2009 and 2012, 18 hips in 17 patients (one patients had bilateral) dislocations were treated by repeat open reduction at our institute. One patient required revision of both hips. Fourteen of the hips were in girls and three in boys; 14 were left hips and 4 right.

The radiographs taken immediately before the repeat procedure were evaluated for the presence of avascular necrosis, coxa magna, and the degree of displacement (see Figure 1). The latest available radiograph was graded according to the revised Severin classification [8]. All patients were reviewed at a minimum of three years after the second reduction (mean 42.4 months; range 37 to 76 ).

The Acetabular Index Angle

The acetabular index was measured as the main variable to evaluate the correction of the acetabular dysplasia and the subsequent maintenance thereof. The term acetabular index was introduced by Kleinberg and Lieberman of New York in 1936 to make a radiographic sign [9]. "The angle formed between the roof or iliac portion of the acetabulum and a horizontal line passing through the triradiate cartilages".

\section{Meaning Length}

The hip is held in place with both hip and knees neutral extension, We used a ruler for measuring length and compared both lower limb for "Leg-length Discrepancy", performing begins anterior superior iliac spine to lateral top ankle.

The mean age at primary open reduction was 24 months (13 to 36). The second reduction was performed at a mean age of 26.3 months (17 to 42 ) and the mean age at final follow-up was 79.7 months (58 to 105). The mean 
time follow-up was 42.4 months (37 to 76 ).

Operative and clinical records were then reviewed to identify those patients who needed a second open reduction of the hip because of redislocation. Clinical and operative records were retrospectively reviewed for both cohorts to determine demographic information, clinical data, length of follow-up, and which additional procedures were performed at the time of the initial open reduction. For the study population, the time to redislocation was noted as well as the number and nature of the subsequent procedures that were performed. Operative notes from the revision surgeries were examined to determine the surgeon's subjective reason for the redislocation.

\subsection{The Primary Treatment (Table1)}

In 18 patients the fact that reduction had not been achieved by the primary open reduction was recognized be-

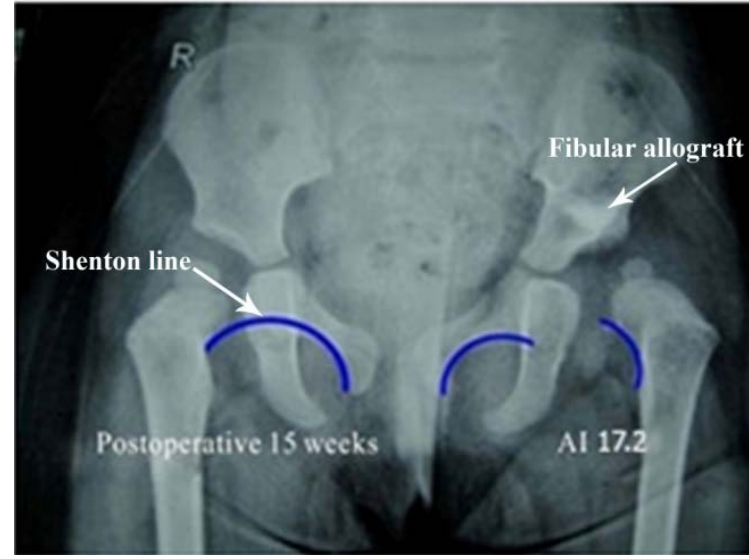

(a)

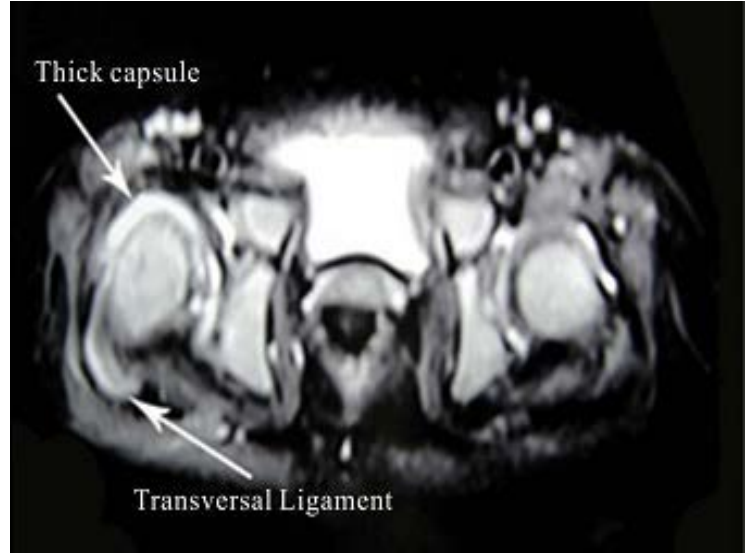

(b)

Figure 1. Postoperatively 15 weeks, left hip with subluxation: (a) Roentgenography shown acetabular index with normal limits; Broken Shenton line; (b) MRI shown thick capsule and hypertrophic transverse ligamentum.

Table 1. Details of primary treatment and later operations in 18 hips with congenital dislocation requiring repeat open reduction.

\begin{tabular}{|c|c|c|c|c|c|}
\hline Cases & Sex & Side & Age at first open reduction (Mo) & Associated operation* & Time to recognition of failure (Mo) \\
\hline 1 & $\mathrm{~F}$ & $\mathrm{R}$ & 18 & $\mathrm{ZO}+\mathrm{FA}+\mathrm{AT}+\mathrm{KW}$ & 4 \\
\hline 2 & M & $\mathrm{L}$ & 15 & $\mathrm{ZO}+\mathrm{FA}+\mathrm{FO}+\mathrm{KW}$ & 2 \\
\hline 3 & $\mathrm{~F}$ & $\mathrm{~L}$ & 18 & $\mathrm{ZO}+\mathrm{FA}+\mathrm{KW}$ & 3 \\
\hline 4 & $\mathrm{~F}$ & $\mathrm{~L}$ & 26 & $\mathrm{ZO}+\mathrm{FA}+\mathrm{FO}+\mathrm{KW}$ & 4 \\
\hline 5 & $\mathrm{~F}$ & $\mathrm{R}$ & 19 & $\mathrm{ZO}+\mathrm{FA}+\mathrm{AT}+\mathrm{KW}$ & 5 \\
\hline 6 & $\mathrm{~F}$ & $\mathrm{~L}$ & 14 & $\mathrm{ZO}+\mathrm{FA}+\mathrm{KW}$ & 12 \\
\hline 7 & $\mathrm{~F}$ & $\mathrm{~L}$ & 34 & $\mathrm{ZO}+\mathrm{FA}+\mathrm{KW}$ & 3 \\
\hline 8 & $\mathrm{~F}$ & $\mathrm{~L}$ & 29 & $\mathrm{ZO}+\mathrm{AT}+\mathrm{FA}$ & 3 \\
\hline 9 & $\mathrm{~F}$ & $\mathrm{~L}$ & 17 & $\mathrm{ZO}+\mathrm{FA}+\mathrm{KW}$ & 8 \\
\hline 10 & M & $\mathrm{L}$ & 22 & $\mathrm{ZO}+\mathrm{FA}+\mathrm{AT}+\mathrm{KW}$ & 2 \\
\hline 11 & $\mathrm{~F}$ & $\mathrm{~L}$ & 18 & $\mathrm{ZO}+\mathrm{FA}+\mathrm{FO}+\mathrm{KW}$ & 5 \\
\hline 12 & $\mathrm{~F}$ & $\mathrm{~L}$ & 36 & $\mathrm{ZO}+\mathrm{FA}+\mathrm{AT}+\mathrm{KW}$ & 6 \\
\hline 13 & $\mathrm{~F}$ & $\mathrm{~L}$ & 19 & $\mathrm{ZO}+\mathrm{FA}+\mathrm{KW}$ & 3 \\
\hline 14 & $\mathrm{~F}$ & $\mathrm{R}$ & 18 & $\mathrm{ZO}+\mathrm{FA}+\mathrm{AT}+\mathrm{KW}$ & 4 \\
\hline 15 & $\mathrm{~F}$ & $\mathrm{~L}$ & 21 & $\mathrm{ZO}+\mathrm{FA}+\mathrm{AT}+\mathrm{KW}$ & 3 \\
\hline 16 & $\mathrm{~F}$ & $\mathrm{~L}$ & 23 & $\mathrm{ZO}+\mathrm{FA}+\mathrm{KW}$ & 4 \\
\hline 17 & M & $\mathrm{R}$ & 27 & $\mathrm{ZO}+\mathrm{FA}+\mathrm{KW}$ & 3 \\
\hline 18 & M & $\mathrm{L}$ & 28 & $\mathrm{ZO}+\mathrm{FA}+\mathrm{AT}+\mathrm{KW}$ & 3 \\
\hline
\end{tabular}

(14 \& 15 are bilateral hip in one patient); ZO: Zigzag osteotomy; FA: Fibular allograft; FO: Femoral derotation varus osteotomy; OR: Open reduction; KW: Kirschner wire stabilization; AT: Adductor tenotomy. 
fore or at the time of plaster removal. In the remainder subluxation developed later. The median time to the recognition of failure was 4.6 months.

In Table 1: there were 18 hips (one patient of them with bilateral hip), 4 of them Male and 13 female, 4 right hips and 14 left hips, Age at first open reduction meaning 24 months (13 to 36), all patient with Open reduction and Zigzag osteotomy combined with fibular allograft, 3 of them Femoral derotation varus osteotomy, all patients with Kirschner wire stabilization, 4 of them with Adductor tenotomy.

\subsection{Technique of Operation}

Each case presents its own individual problems but some basic principles can profitably be discussed. The incision of zigzag osteotomy [7] and approach is most useful, modified as necessary to allow for previous scarring. The capsule is opened widely and the acetabulum is then cleared of the fibro-fatty tissue which may fill it. A Surgeon's finger could through acetabular notch and indentify any obstruction to reduction. Redundant tissue is excised, and the remaining capsule is stitched down to the pelvis, with especial care at the anterior rim of the acetabulum. It was then opened in a T-shaped manner, and the joint was inspected. Adhesions, which were usually dense, were then released. Any obstruction to reduction usually the psoas tendon, the ligamentum teres, the transverse ligament, the limbus or the pulvinar that had not been dealt with at the primary procedure was then released. If the limbus was inverted, it was everted by making radial cuts. The acetabular notch was cleared of scar tissue. Once the hip was reduced, radiography is used to identify whether the hip is.

In cases with anterior displacement mobilisation of the femoral head may not be too difficult, but posterior displacement necessitates very careful dissection around the capsule. The head of the femur often becomes stuck posteriorly and the capsule is drawn across the mouth of the acetabulum, making it very difficult to identify. In a number of cases it was necessary to use a Kirschner wire and radiographs during operation to make sure of the position of the acetabulum.

If, after these soft-tissue procedures, there was still difficulty in reducing the hip, a femoral shortening was performed through a second, lateral incision and in these cases femoral neck anteversion was also corrected. Any redundant posterosuperior capsule was excised and capsular adhesions to the lateral wall of the pelvis were released. Capsulorrhaphy was performed with heavy-duty sutures. In femur which there was significant femoral anteversion, a derotation varus osteotomy was performed ten to twelve weeks after the open reduction.

In some cases, despite all the above steps, the hip was still unstable and in these Kirschner wires were used to maintain concentric reduction. The wire was passed through the greater trochanter and into the ilium above the capsule after capsulorrhaphy and was retained for three weeks.

Postoperative immobilisation in a hip spica was for 6 to 12 weeks depending on the need for a second-stage femoral osteotomy.

The spica cast was applied immediately after surgery, hip in 30 degrees of flexion, 45 - 50 degrees of abduction, and $20^{\circ}-30^{\circ}$ degrees of internal rotation.

The reduction was confirmed clinically and by intra-operative radiographs. Post-operative immobilisation in a hip spica was maintained for 10 - 12 weeks.

We evaluating Post-Operative result combined Radiological according to the Severin [8], Kalamchi [3] (Table 2) and Clinical be using the modified McKay criteria [10] [11] (Table 3).

\section{Results}

Between 2009 and 2012, 178 patients (bilateral hips in 13 patients) with 191 hips have been open operated zizag osteotomy combined fibular allograft. There were 18 hips in 17 patients (one patients had bilateral) redislocation $(9.1 \%)$ were treated by repeat open reduction at our Institute by the same surgery.

All hips were cleared of scar tissue; Five hips with adductor tenotomy; Four hips required release of the psoas tendon, five eversion of the limbus. release of the transverse ligament was required in five case each. The case 6 , eversion of the limbus and adhesions with ligamentum teres (see Figure 2). All hips with Kirschner wire (Kwire) through the femoral head into the acetabulum. Three hips required femoral shortening (average of $1.5 \mathrm{~cm}$ ); a derotation varus osteotomy was performed in two hips from ten and twelve weeks after repeat open reduction.

\section{Evaluating Operative Results}

Overall, Postoperative results according to modified McKay criteria for clinica: Excellent: 3 of 18 hips (16.7\%); 
Table 2. Details of radiological according to the Severin [8] and Kalamchi [3] classifications.

\begin{tabular}{cl}
\hline Classifications & \\
\hline Severin & Description \\
\hline 1 & Moderate deformity of femoral head or neck or acetabulum \\
2 & Dysplastic no subluxed \\
3 & Subluxed \\
4 & Head articulating with secondary acetabulum in upper of the original acetabulum \\
5 & Dislocated \\
6 & Arthritic \\
7 & Changes affecting the ossific nucleus \\
\hline Kalamchi & Lateral physeal damage \\
\hline 1 & Central physeal damage \\
\hline & Total damage to the head and physis \\
\hline
\end{tabular}

Table 3. Modified McKay criteria for clinical evaluation [9] [10].

\begin{tabular}{cl}
\hline Grad & \multicolumn{1}{c}{ Critia } \\
\hline Excellent & Stable, painless hip; no limp; negative Trendelenburg sign; full range of movement \\
Good & Stable, painless hip; slight limp; slight decrease in range of movement \\
Fair & Stable, painless hip; limp; positive Trendelenburg sign; and limited range of movement or a combination of these \\
Poor & Unstable or painful hip or both; positive Trendelenburg sign \\
\hline
\end{tabular}

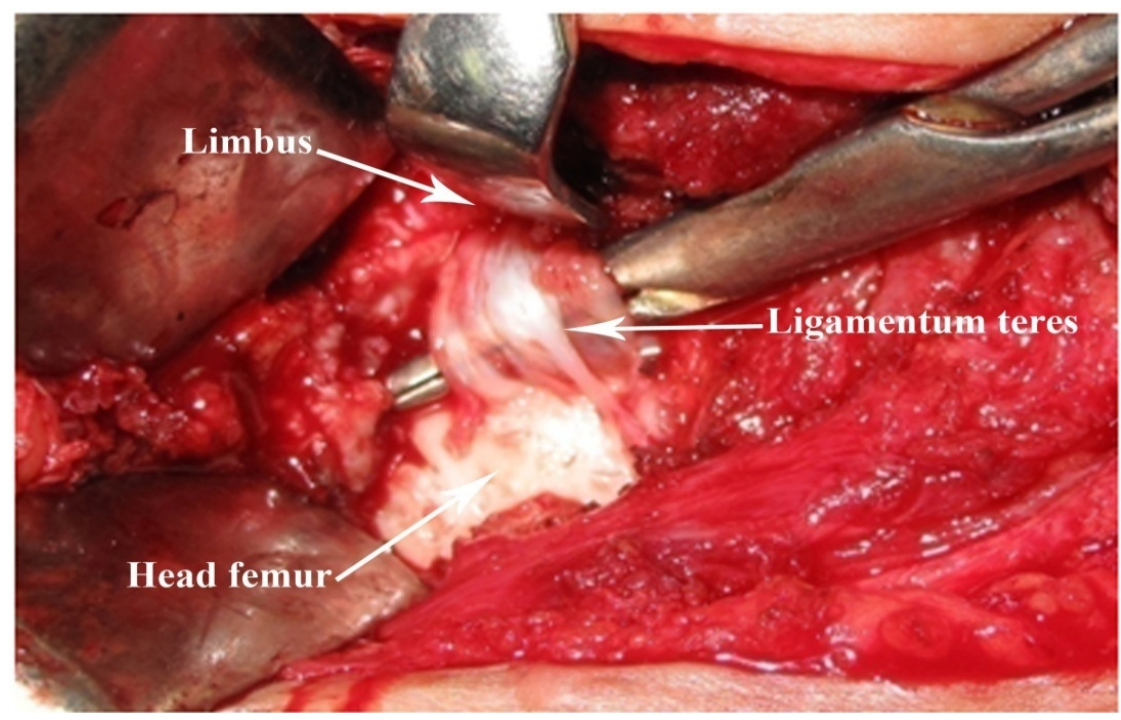

Figure 2. Eversion of the limbus and adhesions with ligamentum teres.

Good: 8 of 18 hips (44.4\%); Fair: 6 of 18 hips (33.3\%); Poor: 1 of 18 hips (5.6\%). Excellent and Good: 11 of 18 hips $(61.1 \%)$

\section{Discussion}

Radiological evaluation demonstrated that zigzag osteotomy combined fibular allograt produced [8] similar results to the original osteotomy. The acetabular index was restored to within normal limits in the immediate 
post-operative period and continued to improve thereafter. Lin et al. [12] reported a mean of $13^{\circ}$ of correction, whereas Bohm and Brzuske [13] reported a mean of $11.9^{\circ}$ of correction with a Salter osteotomy. It et al. [14] reported a mean $16.4^{\circ}$ improvement in the acetabular index. The mean correction of $18^{\circ}$ in this series was comparable to those reported in the literature. Rab [15] estimated that the Salter innominate osteotomy provides about 15 degrees of lateral coverage and 25 degrees of anterior coverage, although many clinicians believe that more lateral coverage can be obtained. in this study was comparable to those reported in the literature. In the literature, the rate of graft displacement ranges between $0 \%$ and $17 \%$ [11]-[14]. In zigzag osteotomy combined fibular allograt, the rate of graft displacement was $0 \%$. This postoperative result of graft may be the result of the care taken to verify the stability of the graft with this technique. An initial increased acetabular index reflects the absence of normally located femoral epiphysis and its stimulus in the acetabulum [16]. This may indicate that this complication is a real failure of the previous closed and open reduction, instead of a redislocation, when some acetabular improvement must appear in acetabular index values. In this study, the mean correction of $18.54^{\circ}$ (range, $14.08^{\circ}-21.83^{\circ}$ ), we demonstrated that acetabular index was continued to improve and it is not cause for the redislocation or resubluxation (see Table 4).

All the patients were treated by a further open operation to reduce the displaced femoral head; this was frequently a technically demanding procedure because of dense scarring. Examination under anaesthesia and screening with an image intensifier can be very useful before operation. Arthrography is often difficult because of intra-articular scarring. CT scans were not used routinely but are very useful when the bony architecture is distorted on plain radiography. CT scanning can show the position and shape of the femoral head relative to the acetabulum and also the shape of the acetabulum; this may have become grossly distorted or even destroyed after previous treatment [17].

Most instances of failure to obtain stable reduction at the initial operation were the result of errors in surgical technique or judgement. In many cases the previous skin incision had been placed where it would have been very difficult to obtain an adequate exposure, even allowing for possible migration of the incision with growth.

The anteromedial approach occasionally used as primary treatment for open reduction in congenital dislocation of the hip, because of its directness, simplicity and effectiveness for children under 2 years of age [3] [9] [12]. However, most orthopaedic surgeons prefer the anterolateral approach, as it allows eversion of the limbus, capsulorraphy and a simultaneous pelvic osteotomy. However, limbectomy is not always necessary and it may involve acetabular development, requiring secondary procedures [18] [19].

This anterolateral approach has been chosen and treating previous failed open reduction [5] [6]. All of them considered in their surgical revisions that the anteromedial approach area was the problem. On the basis of these experiences, we chose anteromedial approach approach going directly to this area, although an anterolateral approach could be useful also, and less technically demanding. The anteromedial approach allows the release of the adductor longus, before open reduction, through the same incision. The approach also allows easy reaching of the psoas tendon, transverse ligament and the constricted anteromedial capsule [18] [6].

These anteromedial obstacles are common in the first open reduction, and they are the main problems in the failure of open reduction [6]. All our patients showed an intact anteromedial capsule, after the anterior capsulotomy. It was also possible to remove the intraarticular adhesions (see Figure 3) and to clean the acetabulum through this approach [20].

In a more recent study, Chidambaram et al. [21] described 12 patients (11 referrals) who required revision surgery for failed open reduction. Most failures were again attributed to inadequate release of the transverse acetabular ligament and incomplete capsulotomy.

Most of the patients had not had an adequate soft-tissue release or sufficient clearance of the structures which obstruct reduction of the head into the acetabulum. Both of these procedures may make it difficult to ap-

Table 4. Acetabukar index angle primary and at second open reduction.

\begin{tabular}{cccc}
\hline Acetabular index & Preope. AI & Immediate Postope. AI & AI. at second open reduction \\
\hline Average & 42.14 & 22.56 & 18.54 \\
SD & 4.318 & 2.432 & 1.798 \\
Range & $36.17-50.56$ & $18.22-24.35$ & $14.08-21.83$
\end{tabular}

The acetabular index before open reduction and at repeat open reduction. Acetabular index at repeat open reduction is average $18.54^{\circ}$ (range, $14.08^{\circ}$ $\left.21.83^{\circ}\right)$. 


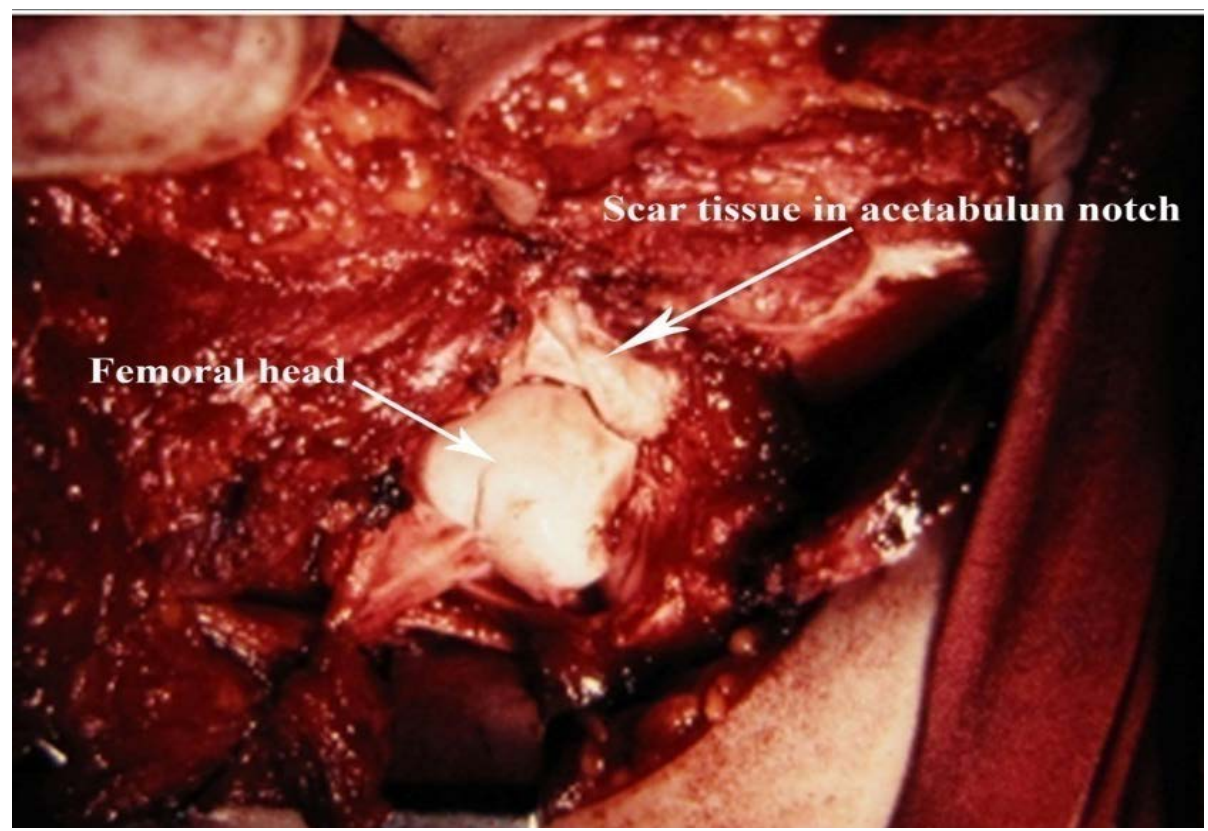

Figure 3. Scar tissue in acetabular notch.

preciate the proper position of the femoral head in relation to the acetabulum, and may compromise the capsulorrhaphy. The success of the capsular repair is very important in the first few weeks after open reduction; undue tension applied either anteriorly or posteriorly may cause dehiscence or stretching. In many revision cases, the capsule was much scarred, and an adequate capsulorrhaphy was not possible. We have to do thin capsule so could be done. Failure to tighten the posterior capsule may lead to posterior subluxation of the head, especially if an osteotomy has been performed simultaneously. Our findings in these respects agree with those of Bos and Sbooff [5] and McCluskey et al. [2].

A capsulorrhaphy was performed. In many revision cases, the capsule was very scarred, and an adequate capsulorrhaphy was not possible. There were 5 hips of them (see Table 5) in this study with densing anterior capsule in this study, they have been performed to do thin anterior capsule so could be done. As our patients did not have a simultaneus osteotomy at the time of first open reduction, and all primary surgeons felt convinced that a good superior capsulorraphy was obtained, we directed our surgery to the anteromedial area of hip joint. We felt that closed reduction would be unsuccessful because of the significant scarring from previous surgery and that the anteromedial approach should be used [2] (see Figure 3).

The most common finding at the time of revision surgery was abnormal femoral version, and none of these patients had had a previous derotational osteotomy. Our institute has previously shown wide variability in femoral version in children with DDH [22]. On the basis of this study, we have moved toward a more individualized surgical plan based on a child's specific degree of femoral anteversion, and now favor derotational femoral osteotomy for those children who have greater than 60 degrees of femoral anteversion at the time of open reduction. Optimization of femoral version may have a beneficial effect on acetabular development by redirecting the resultant forces of muscles around the proximal femur more directly toward the acetabulum. The retrospective nature of this study, however, limited our ability to gather objective data regarding femoral version and therefore we are unable to draw definitive conclusions. The next stage in their treatment was to correct excessive femoral anteversion since they believed that reduction could be stabilised by this manoeuvre. The belief that a rotation osteotomy conferred stability is based on the assumption that a deeply placed and correctly centred femoral head stimulates normal growth of the dysplastic acetabulum. Indeed, Harris, Lloyd Roberts and Gallien [23] suggested that, following congruent reduction, $95 \%$ of acetabula would develop normally in children up to four years old.

A common factor in the patients with redislocation in the fourth group was performing Salter innominate osteotomy along with femoral shortening and derotation. This group has the most amount of patients with redislocation $(\mathrm{P}<0.05)$, although uncorrected femoral anteversion is the cause of redislocation according to Wang et al. [24], good results have and combining derotational femoral shortening osteotomy with open reduction to reduce 
Table 5. Previous operation in 18 hips with congenital dislocation requiring repeat open reduction.

\begin{tabular}{|c|c|c|c|c|c|}
\hline Cases & Preoperative state & Operation finding & Anterior Capsule deficient & Posterior Subluxation & Associated operation \\
\hline 1 & $\mathrm{~S}$ & $\mathrm{~EB}, \mathrm{P}$ & - & + & AT, AS. KW \\
\hline 2 & $\mathrm{~S}$ & LT, TL & + & - & FS, AS, KW \\
\hline 3 & S & LT, P, DC & + & - & AT, AS, KW \\
\hline 4 & $\mathrm{~S}$ & TL, P & - & - & , AS, KW \\
\hline 5 & S & LT, P, DC & - & + & AS, KW \\
\hline 6 & $\mathrm{~S}$ & TL, EB & - & - & $\mathrm{AT}, \mathrm{AS}, \mathrm{KW}$ \\
\hline 7 & $\mathrm{~S}$ & TL, PS & - & - & $\mathrm{FO}, \mathrm{AS}, \mathrm{KW}$ \\
\hline 8 & $\mathrm{~S}$ & LT, PS & - & - & AS, KW \\
\hline 9 & $\mathrm{~S}$ & $\mathrm{~EB}, \mathrm{P}, \mathrm{DC}$ & - & + & $\mathrm{AS}, \mathrm{KW}$ \\
\hline 10 & $\mathrm{~S}$ & LT, P & + & - & $\mathrm{FO}, \mathrm{AS}, \mathrm{KW}$ \\
\hline 11 & $\mathrm{~S}$ & LT, P, PS & - & + & AS, KW \\
\hline 12 & $\mathrm{~S}$ & LT, P & + & - & AS, KW \\
\hline 13 & $\mathrm{~S}$ & $\mathrm{TL}, \mathrm{EB}, \mathrm{DC}$ & + & - & FS, AS, KW \\
\hline 14 & $\mathrm{D}$ & LT, P & - & - & AS, KW \\
\hline 15 & $\mathrm{D}$ & P, PS & - & - & AT, AS, KW \\
\hline 16 & S & LT, TL, P & - & - & AS, KW \\
\hline 17 & S & T P, EB & - & - & $\mathrm{AT}, \mathrm{AS}, \mathrm{FS}, \mathrm{KW}$ \\
\hline 18 & $\mathrm{~S}$ & LT, EB, DC & + & - & AS, KW \\
\hline
\end{tabular}

D: Dislocation; Subluxation; LT: Ligamentum teres present; PS: Psoas tendon; P: Puvinar present; TL: Transverse ligament present; AT: Adductor tenotomy; FO: Femoral varus derotation osteotomy; FS: Femoral shortening; KW: Kirschner wire; AS: Acetabular was cleared of Scar tissue; EB: Eversion of the limbus; DC: Densing anterior capsule (see Figure 4).

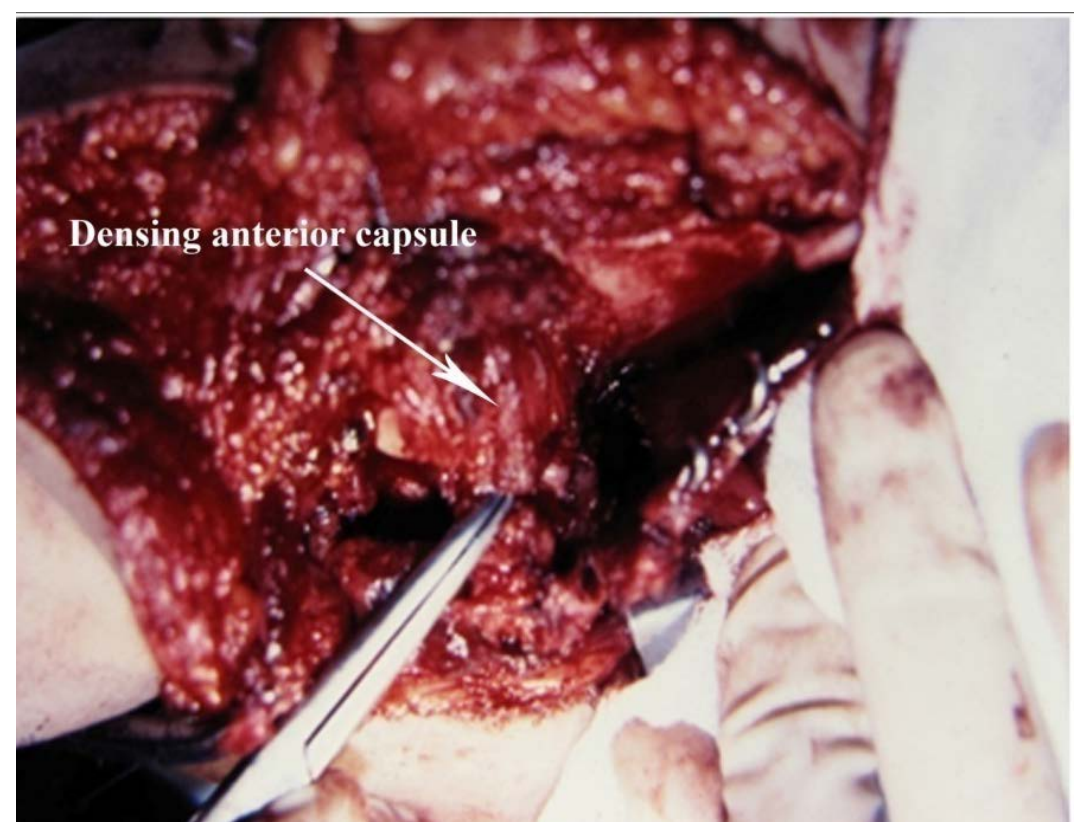

Figure 4. Densing anterior capsule.

the incidence of redislocation in DDH was first used for older children been reported by some authors [25]-[27], but, the combination of the Salter innominate osteotomy with femoral derotation makes the posterior wall of the acetabulum uncovered and the risk of the posterior dislocation increases by the combination of these two operations [28]. This study, it is associated with increased femoral anteversion which will require correction. So four 
to six weeks later repeated open reduction a subtrochanteric derotation femoral osteotomy was performed. After a further six weeks in a hip spica the child was allowed to mobilise freely.

The most common reason for failure, based on findings during the revision surgery, was improper exposure and release of the inferior capsule and transverse acetabular ligament. Other factors that were implicated with failure of treatment were difficulties with spica immobilization and excessive derotation of the femur. In all, failure to maintain reduction could be attributed to an inadequate soft tissue release or insufficient clearance of the structures, which obstruct reduction.

This fact emphasizes the need for the open reduction of DDH to be performed by experienced paediatric orthopaedic surgeons. The bilateral dislocations, treated primarily at our institution, had no definitive soft tissue obstruction evident at re-operation apart from adhesions and pulvinar tissue. As in all the previous reports [5] [1], the poor final clinical and radiographic results reflect the numerous procedures performed in these children to obtain a stable, concentric reduction. We suggest that technical failure namely inadequate soft tissue release is usually the cause for re-dislocation in unilateral dislocations (see Table 6). In bilateral dislocations, no obvious reason was evident, and it may be that the biological behaviour of these hips is in some way different.

Resubluxation occasionally occurs anteriorly but only rarely posteriorly. With increasing experience, it became clear that the clinical signs could help to differentiate the direction of displacement. While all patients showed shortening and a limp, those with anterior displacement tended to retain a reasonable range of movement at the hip, which was held in lateral rotation, with little or no range of medial rotation. By contrast, hips with posterior displacement showed marked stiffness, were held in medial rotation, often with some flexion, and allowed little or no lateral rotation. An anteriorly displaced head of femur was sometimes palpable in the groin, but in cases with marked anterior displacement, the greater trochanter is easily palpable in the buttock and can be mistaken for the femoral head. In two patients, attempts to repeat the open reduction had been abandoned as impossible by the referring surgeon [5] [17].

Our experience bears out this contention. Anterior displacement after osteotomy is very much easier to deal with than posterior displacement because there is usually less scarring and less distortion of the femoral head. However, it is associated with increased femoral anteversion which will require correction, either at the same time as the open reduction or preferably at a second-stage femoral osteotomy.

Table 6. Clinical and radiological results in 18 hips after repeat open reduction for congenital dislocation. (see Table 2 \& Table 3 for details for classifications).

\begin{tabular}{|c|c|c|c|c|c|c|}
\hline Case & $\begin{array}{l}\text { Time of Follow-up } \\
\text { (Mon) }\end{array}$ & $\begin{array}{l}\text { Age at follow-up } \\
\text { (Mon) }\end{array}$ & $\begin{array}{c}\text { Severin } \\
\text { grade }\end{array}$ & $\begin{array}{l}\text { Kalamchi } \\
\text { grade }\end{array}$ & $\begin{array}{l}\text { Leg-length Discrepancy } \\
\text { (Cm) }\end{array}$ & $\begin{array}{c}\text { Modified McKay's criteria } \\
\text { evaluation }\end{array}$ \\
\hline 1 & 36 & 58 & 3 & 1 & 1 & Good \\
\hline 2 & 41 & 58 & 2 & 4 & 2 & Fair \\
\hline 3 & 48 & 69 & 1 & $\mathrm{O}$ & $\mathrm{O}$ & Excellent \\
\hline 4 & 75 & 105 & 3 & $\mathrm{O}$ & 1 & Fair \\
\hline 5 & 68 & 92 & 3 & 2 & 2 & Fair \\
\hline 6 & 74 & 100 & 2 & 3 & 2 & Fair \\
\hline 7 & 43 & 85 & 2 & 3 & 1 & Fair \\
\hline 8 & 39 & 71 & 1 & 1 & $\mathrm{O}$ & Good \\
\hline 9 & 65 & 90 & 1 & 1 & $\mathrm{O}$ & Good \\
\hline 10 & 62 & 86 & 1 & $\mathrm{O}$ & $\mathrm{O}$ & Exellent \\
\hline 11 & 57 & 80 & 3 & 4 & 1 & Poor \\
\hline 12 & 66 & 98 & 1 & $\mathrm{O}$ & $\mathrm{O}$ & Excellent \\
\hline 13 & 44 & 66 & 2 & $\mathrm{O}$ & $\mathrm{O}$ & Good \\
\hline 14 & 56 & 78 & 2 & 1 & 1 & Fair \\
\hline 15 & 53 & 78 & 2 & 1 & $\mathrm{O}$ & Good \\
\hline 16 & 41 & 68 & 1 & $\mathrm{O}$ & 1 & Good \\
\hline 17 & 42 & 72 & 2 & $\mathrm{O}$ & 1 & Good \\
\hline 18 & 48 & 79 & 2 & 1 & 2 & Good \\
\hline
\end{tabular}


Posterior re-displacement produces the characteristic clinical signs of a stiff, adducted, flexed, medially rotated hip. Like posterior displacement of the shoulder it can easily be missed on early postoperative radiographs. The major problems at re-exploration in these cases are the mobilisation of the femoral head from its posterior position, the probable deformity of the femoral head and the identification and clearance of the acetabulum [17].

Our experience bears out this contention. Anterior displacement after osteotomy is very much easier to deal with than posterior displacement because there is usually less scarring and less distortion of the femoral head. Posterior re-displacement produces the characteristic clinical signs of a stiff, adducted, flexed, medially rotated hip. Like posterior displacement of the shoulder it can easily be missed on early postoperative radiographs. The major problems at re-exploration in these cases are the mobilisation of the femoral head from its posterior position, the probable deformity of the femoral head and the identification and clearance of the acetabulum.

The exact cause of the redisplacement after osteotomy is difficult to determine but it is likely, as listed by Tachdjian [29] that the main factors are a poorly executed osteotomy, a lax capsulorrhaphy and excessive femoral anteversion.

Anterior displacement is due to deformity of the upper part of the femur. Posterior displacement is due to posterior acetabular defects. Computerized tomography is needed for this type of displacement. Roth observed 4 redislocations in the secondary group, which he attributed to incomplete reduction, insufficient capsulorrhaphy, and/or insufficient immobilization [30]. Insufficient capsular repair can also lead to redislocation [31]. Tachdjian, Fixen and Haidar established weak fixation of the osteotomy region, a lax capsule, and femoral over-anteversion as reasons for redislocation and resubluxation

The abduction in the spica cast was significantly higher in the control patients (mean 50.8 degrees) compared with those who failed open reduction (mean 38.8 degrees). Increased abduction in the spica cast is likely effective for 2 reasons. First, abduction can prevent redislocation during the casting period by directing forces more perpendicular to the mouth of the acetabulum, and second, increased abduction may improve acetabular remodeling during the period of immobilization so that the acetabulum is a better shape upon cast removal. Salter and others have warned against immobilization in excessive abduction as this increases the risk of osteonecrosis [32] [33] but to our knowledge, the correlation between abduction and osteonecrosis has only been shown in flexed hips after closed reduction, not the relatively extended position after open reduction. Salter, himself, preferred a spica cast with the hip placed in slight flexion, approximately 45 degrees of abduction, and mild internal rotation to maintain a concentric reduction. Our patients in this study with abduction in the spica cast mean 39.2 degrees at previous surgery and postoperative repeated open reduction was 51.4 degrees.

\section{Conclusions}

We suggest that technical failure is usually the cause for re-dislocation with all that have an intact anteromedial capsule. There was an inverted transverse ligament, tight psoas tendon, eversion of the limbus, and densing anterior capsule in five cases. There was an inverted transverse ligament and a very tight psoas tendon, eversion of the limbus, densing anterior capsule. We performed with all hips that were cleared of scar tissue; adductor tenotomy; hips required release of the psoas tendon, eversion of the limbus; release of the transverse ligament was required. All hips with Kirschner wire (Kwire) were through the femoral head into the acetabulum. The hips required femoral shortening (average of $1.5 \mathrm{~cm}$ ); a derotation varus osteotomy should be performed in hips from ten and twelve weeks after repeated open reduction.

Limitations of this study included the following. This was studied with small data and with a relatively short follow-up period. Not all the included patients were followed till skeletal maturity, which is of critical importance, as the clinical, as well as radiographic, results tend to vary with time. Nevertheless, this study shows that redislocation of the failure after a primary open reduction was the consequence of errors in surgical technique.

\section{Acknowledgements}

The author would like to thank assistance of our three research assistants in the Orthopaedic Department at National Hospital for Paediatrics, Dr. Le Tuan Anh, Dr. Phung Cong Sang, and Dr. Hoang Hai Duc who are greatly appreciated in general assistance in manuscript preparation.

\section{References}

[1] Hsiech, S.M. and Huang, S.C. (1998) Treatment of Developmental Dysplasia of the Hip after Failed Open Reduction. 
Journal of the Formosan Medical Association, 97, 763-769.

[2] McCluskey, W.P., Bassett, G.S., Mora-Garcia, G. and MacEwen, G.D. (1989) Treatment of Failed Open Reduction for Congenital Dislocation of the Hip. Journal of Pediatric Orthopaedics, 9, 633-639. http://dx.doi.org/10.1097/01241398-198911000-00001

[3] Kalamchi, A. and MacEwen, G.D. (1980) Avascular Necrosis Following Treatment of the Hip. The Journal of Bone \& Joint Surgery, 62, 876-888.

[4] Tonnis, D. (1987) Review of the Literature on Open Reduction of the Hip in Congenital Dysplasia and Dislocation of the Hip in Children and Adults. Springer, Heidelberg, 332. http://dx.doi.org/10.1007/978-3-642-71038-4

[5] Bos, C.F.A. and Slooff, T.J. (1984) Treatment of Failed Open Reduction for Congenital Dislocation of the Hip. Acta Orthopaedica Scandinavica, 55, 531-535. http://dx.doi.org/10.3109/17453678408992953

[6] Kershaw, C.J., Ware, H.E., Pattinson, R. and Fixsen, J.A. (1993) Revision of Failed Open Reduction of Congenital Dislocation of the Hip. The Journal of Bone \& Joint Surgery, 75B, 744-749.

[7] Hung, N.N. (2013) Congenital Dislocation of the Hip in Children between the Ages of One and Three: Open Reduction and Modified Salter Innominate Osteotomy Combined with Fibular Allograft. Open Journal of Orthopedics, 3, 137152. http://dx.doi.org/10.4236/ojo.2013.32026

[8] Severin, E. (1941) Contribution to Knowledge of Congenital Dislocation of Hip Joint : Late Results of Closed Reduction and Arthrographic Studies of Recent Cases. Acta Orthopaedica Scandinavica, 84, 1-142.

[9] Kleinberg, S. and Lieberman, H.S. (1936) The Acetabular Index in Infants in Relation to Congenital Dislocation of the Hip. Archives of Surgery, 32, 1049-1054. http://dx.doi.org/10.1001/archsurg.1936.01180240137007

[10] McKay, D.W. (1974) A Comparison of the Innominate and the Pericapsular Osteotomy in the Treatment of Congenital Dislocation of the Hip. Clinical Orthopaedics and Related Research, 98, 124-132. http://dx.doi.org/10.1097/00003086-197401000-00013

[11] Barrett, W.P., Staheli, L.T. and Chew, D.E. (1986) The Effectiveness of the Salter Innominate Osteotomy in the Treatment of Congenital Dislocation of the Hip. The Journal of Bone and Joint Surgery. American Volume, 68, 79-87.

[12] Lin, C.J., Lin, Y.T. and Lai, K.A. (2000) Intraoperative Instability for Developmental Dysplasia of the Hip in Children 12 to 18 Months of Age as a Guide to Salter Osteotomy. Journal of Pediatric Orthopaedics, 20, 575-578. http://dx.doi.org/10.1097/01241398-200009000-00006

[13] Bohm, P. and Brzuske, A. (2002) Salter Innominate Osteotomy for the Treatment of Developmental Dysplasia of the Hip in Children: Results of Seventy-Three Consecutive Osteotomies after Twenty-Six to Thirty-Five Years of Follow-Up. The Journal of Bone and Joint Surgery. American Volume, 84, 178-186.

[14] Ito, H., Ooura, H., Kobayashi, M. and Matsuno, T. (2001) Middle-Term Results of Salter Innominate Osteotomy. Clinical Orthopaedics and Related Research, 387, 156-164. http://dx.doi.org/10.1097/00003086-200106000-00021

[15] Rab, G.T. (1978) Biomechanical Aspects of Salter Osteotomy. Clinical Orthopaedics and Related Research, 132, 82-87. http://dx.doi.org/10.1097/00003086-197805000-00017

[16] Albinana, J., Morcuende, J.A. and Weinstein, S.L. (1996) The Teardrop in Congenital Dislocation of the Hip Diagnosed Late. A Quantitative Study. The Journal of Bone and Joint Surgery. American Volume, 78, 1048-1055.

[17] Fixsen, J.A. (1987) Anterior and Posterior Displacement of the Hip after Innominate Osteotomy. The Journal of Bone and Joint Surgery. British Volume, 69, 361-364.

[18] Morcuende, J.A., Meyer, M.D., Dolan, L.A. and Weinstein, S.L. (1997) Longterm Outcome after Open Reduction through an Anteromedial Approach for Congenital Dislocation of the Hip. The Journal of Bone and Joint Surgery. American Volume, 79, 810-817.

[19] Mankey, M.G., Arntz, G.T. and Staheli, L.T. (1993) Open Reduction through a Medial Approach for Congenital Dislocation of the Hip. A Critical Review of the Ludloff Approach in Sixty-Six Hips. The Journal of Bone and Joint Surgery. American Volume, 75, 1334-1345.

[20] O’Hara, J.N., Bernard, A.A. and Dwyer, N.S. (1988) Early Results of Medial Approach Open Reduction in Congenital Dislocation of the Hip: Use before Walking Age. Journal of Pediatric Orthopaedics, 8, 288-294. http://dx.doi.org/10.1097/01241398-198805000-00007

[21] Chidambaram, S., Abd Halim, A.R., Yeap, J.K., et al. (2005) Revision Surgery for Developmental of the Hip. Medical Journal of Malaysia, 60, 91-98.

[22] Sankar, W.N., Neubuerger, C.O. and Moseley, C.F. (2009) Femoralanteversion in Developmental Dysplasia of the Hip. Journal of Pediatric Orthopaedics, 29, 885-888. http://dx.doi.org/10.1097/BPO.0b013e3181c1e961

[23] Harris, N.H., Lloyd-Roberts, G.C. and Galilen, R. (1975) Acetabular Development in Congenital Dislocation of the Hip: With Special Reference to the Mdications for Acetabuloplasty and Pelvic or Femoral Realignment Osteotomy. The Journal of Bone and Joint Surgery. British Volume, 57, 46-52. 
[24] Wang, Y., Ji, H. and Lu, B. (1984) Causative Analysis of Redislocation after Operative Reduction of Congenital Dislocation of Hip. Chinese Journal of Reparative and Reconstructive Surgery, 12, 28-30.

[25] Forlin, E., da Cunha, L.A.M. and Figueiredo, D.C. (2006) Treatment of Developmental Dysplasia of the Hip after Walking Age with Open Reduction, Femoral Shortening and Acetabular Shortening. Orthopedic Clinics of North America, 37, 149-160. http://dx.doi.org/10.1016/j.ocl.2005.11.005

[26] Nakmura, M., Matsunaga, S., Yoshino, S., Ohnishi, T., Higo, M., Ohnishia, T., Higob, M., Sakouc, T. and Komiyaa, S. (2004) Long Term Result of Combination of Open Reduction and Femoral Derotation Varus Osteotomy with Shortening for Developmental Dislocation of the Hip. Journal of Pediatric Orthopaedics, Part B, 13, 248-253. http://dx.doi.org/10.1097/01.bpb.0000111030.02081.b1

[27] Wenger, D.R., Lee, C.S. and Kolman, B. (1995) Derotation Femoral Shortening for Developmental Dislocation of the Hip: Special Indications and Results in the Children Younger than 2 Years. Journal of Pediatric Orthopaedics, 15, 768-779. http://dx.doi.org/10.1097/01241398-199511000-00009

[28] Hering, J.A. (2008) Tachdjian's Pediatric Orthopedics. 4th Edition, Vol. 1, Saunders, Philadelphia, 711.

[29] Tachdjian, M.O. (1982) Congenital Dislocation of the Hip. Churchill Livingstone, New York.

[30] Roth, A.D., Gibson, A. and Hall, J.E. (1974) The Experience of Five Orthopaedic Surgeons with Innominate Osteotomy in the Treatment of Congenital Dislocation and Subluxation of the Hip. Clinical Orthopaedics and Related Research, 98, 178-182. http://dx.doi.org/10.1097/00003086-197401000-00020

[31] Gabuzda, G.M. and Renshaw, T.S. (1992) Current Concepts Review. Reduction of Congenital Dislocation of the Hip. The Journal of Bone and Joint Surgery, American Volume, 74, 624-631.

[32] Moseley, C.F. (2008) Open Reduction of Congenital Dislocated Hip and Salter Innominate Osteotomy. Lippincott Williams Wilkins, Philadelphia, 121-135.

[33] Gresgosiewicz, A. and Wosko, I. (1988) Risk Factors for Avascular Necrosis in the Treatment of Congenital Dislocation of the Hip. Journal of Pediatric Orthopaedics, 8, 17-19. http://dx.doi.org/10.1097/01241398-198801000-00004 